\title{
Assessment of knowledge and utilization of Below Poverty Line (BPL) Schemes among BPL families
}

\author{
Mrs Minu Joseph ${ }^{1}$, Mrs Ansuya $^{2}$, MrsManjula $^{3}$ \\ ${ }^{1}$ MSc Nursing Student, ${ }^{2}$ Asst. Professor, Dept of Community Health Nursing, Manipal College of Nursing \\ Manipal, Manipal University, Manipal. ${ }^{3}$ Asst. Professor, Dept of Community Health Nursing, Manipal College \\ of Nursing Manipal, Manipal University, Manipal.
}

\begin{abstract}
:
Background: Below Poverty Line is an economic benchmark and poverty threshold used by the Government of India to indicate economic disadvantage and to identify individuals and households in need of government assistance and aid ${ }^{l}$. According to the poverty report by planning commission of Government of India headed by Shri S. D. Tendulkar constituted to estimate poverty, reported that nearly 38\% of India's population (380 million) is poor. ${ }^{2}$. The BPL cards are distributed after identifying the households based on population based

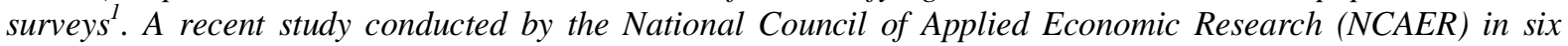
states found that $40 \%$ of the BPL cards have been issued to people who are above the poverty line (APL).The state-level analysis suggests that the extent of misuse of BPL card is highest in Andhra Pradesh followed by Karnataka and Kerala.

Objective : To assess the knowledge of BPL families regarding the BPL schemes by knowledge questionnaire, assess the utilization of BPL schemes by BPL families by utilization questionnaire and to find the association between knowledge and selected variables like education, type of family, type of card they holds.

Design and methods: Research approach was quantitative approach and design was descriptive survey approach. Data was collected by house to house survey.

Setting: Adopted villages of Manipal College of Nursing, Manipal

Participants: 200 BPL families selected by purposive sampling method.

Results: Majority (85.5\%) of subjects had poor knowledge and (14.5\%) average knowledge regarding the BPL schemes. The findings of utilization reveal that Basavavasathi scheme (64\%), and BPL ration scheme (58\%) SuvarnaGramodayaYojana(4\%)Swarnajayanthi Gram SarojgarYojana(19.5\%), Mahatma Gandhi National Rural Employment Guarantee Scheme (14\%), Nirmal Bharat Abhyian(15.5\%) JananiSurakshaYojana(77.8\%)Bhaghyalakshmi scheme (54.2\%)and old age pension (55.4\%) respectively.Knowledge had a significant association between education $\left(\chi^{2}=11.866, p<0.05\right)$ and type of family $\left(\chi^{2}=4.118, p<0.05\right)$.
\end{abstract}

Key words: Knowledge, Utilization

\section{Introduction}

Below Poverty Line is an economic benchmark and poverty threshold used by the Government of India to indicate economic disadvantage and to identify individuals and households in need of government assistance and aid $^{1}$.

The BPL cards are distributed after identifying the households based on population based surveys. So far, three BPL surveys - 1992, 1997 and 2002 - have been conducted throughout the country using three different methodologies. In Karnataka the BPL family is selected on the basis of an annual income of not more than 11,800/-, those who do not have an own two wheeler, a phone connection, and a loan more than 1 lakh. The major BPL schemes running in Karnataka are JananiSurakshaYojana, Vajpayee Arogyasri, BhaghyalakshmiYojana, BasavaVasathiYojana, Old Age Pension Scheme, BPL Ration Scheme, Nirmal Bharat Abhiyan, Mahatma Gandhi National Rural Employment Guarantee Scheme, SuvarnaGramodhyaYojana, Swarnajayanthi Gram SarojgarYojana, and RasthriyaSwasthiyaBimaYojana ${ }^{1}$.

A recent study conducted by the National Council of Applied Economic Research (NCAER) in six states found that $40 \%$ of the BPL cards have been issued to people who are above the poverty line (APL).The state-level analysis suggests that the extent of misuse of BPL card is highest in Andhra Pradesh followed by Karnataka and Kerala ${ }^{2}$.Over 15 years of growth in India, $46 \%$ of the children in the country are still undernourished. (NFHS, 2005/06), about $50 \%$ of the adult females are illiterate, $67 \%$ of the population does not have access to improved sanitation, and $44 \%$ of the population has no access to electricity ${ }^{3}$. By reviewing all these literaturethe researcher intended to assess the knowledge and utilization of all BPL schemes in adopted villages of Manipal College of Nursing, Manipal. 
Objectives:

1. To assess the knowledge of BPL families regarding the BPL schemes by knowledge questionnaire.

2. To assess the utilization of BPL schemes by BPL families by utilization questionnaire.

3. To find the association between knowledge and selected variables like education, type of family, type of card they holds.

Hypothesis:

$\mathrm{H}_{1}$ : There will be a significant association between the knowledge and selected variablessuch as education, type of family and type of card they holds

\section{Materials and methods}

A descriptive survey design was used to assess the knowledgeand utilization of BPL schemes by BPL families residing in adopted villages of Manipal College of Nursing, Manipal. All the BPL families in the adopted villages include the study population and 200 BPL families. The estimated sample size was 114 but the researcher was decided to select 200 samples.Administrative permission was obtained from the Dean, Manipal College of Nursing, Manipal, InstitutionalEthical clearance was obtained from The Institutional Ethics Committee, Kasturba hospital, Manipal and Informedconsents from the participants.

Data collection tools were developed after extensive review of literature and expert Opinion for the development of the tools. The instruments used were demographic proforma, questionnaire on knowledge BPL schemes and utilization of BPL schemes. Thetools were given to seven exerts for their suggestions. All the tools were translated into Kannada and retranslated into English.

Tool 1: Demographic Proforma: Structured demographic proforma was developed by the researcher. The tool consisted of 10 items seeking background information like age, gender, religion, education, occupation, socio economic status, type of family, BPL card number, colour of BPL card and card number. The items in this tool do not have scoring as it reflects factual information. The tool was validated by 7 experts. Translated into kannada and pretested among 5 BPL families.Tool 2: Knowledge Questionnaire on BPL schemes:A structured multiple choice questionnaire was developed with the intention of assessing the knowledge of BPL schemes among BPL families. It consisted of 40 multiple choice items in all BPL schemes available in Karnataka likeJananiSurakshaYojana, Vajpayee ArogyasriYojana, BhagyalakshmiYojana, BasavaVastahiYojana, Old Age Pension Scheme, BPL Ration Scheme, Nirmal Bharat Abhiyan, Mahatma Gandhi National Rural Employment Guarantee Scheme, SuvarnaGramodayaYojana, Swarnajayanthi Gram SwarozgarYojana, RasthriyaSwasthyaBimaYojana. Each right answer carried a score of 1 and each wrong answer was scored zero. The entire item had four alternative responses. Themaximum total score was 40 and the minimum score was 0 . To analyse and interpret the knowledge level, the total score was arbitrarily classified as follows good knowledge has a score of (28-40), average knowledge (14-27) score and poor knowledge (13-0) score. Pretesting was done among 5 BPL families and reliability was established by split half method(r $=0.92)$ among 20 BPL families.Tool 3: Utilization Questionnaire on BPL Schemes:Structured questionnaire on utilization of BPL schemes was developed to gather information regarding utilization of the available services. This tool comprised of 15 items covering all the schemes available in Karnataka. Each right answer scored 1 and wrong answer scored 0 . The maximum score was 15 and minimum was 0 . The tool was pretested by administering it to five participants residing in Alevoor Village. The reliability of the structured utilization questionnaire was determined by using Kuder Richardson formula(r=0.86).

Data were collected from $14^{\text {st }}$ January to $16^{\text {th }}$ February 2013 in the adopted villages of Manipal College of Nursing, Manipal. The samples were selected by purposive sampling technique by house to house survey and questionnaire was administered.

The data were analysed using both Descriptive and inferential stasticsusing Statistical Package for Social Science Version 16 (SPSS 16). Descriptive statistics: Frequency and percentage distribution were used to describe the sample characteristics.Inferential statistics: Chi Square was used to test the association between knowledge and selected variables like education, type of family and type of card they holds.

\section{Sample characteristics}

\section{Results}

The sample for analysis consisted of 200 BPL families. Frequency and percentage were computed for describing the sample characteristics. 
Table 1: Frequency and percentage distribution of sample characteristics

\begin{tabular}{|c|c|c|}
\hline \multirow[b]{2}{*}{ Variables } & \multicolumn{2}{|c|}{$n=200$} \\
\hline & $\mathrm{f}$ & $\%$ \\
\hline \multicolumn{3}{|l|}{ Age in yrs } \\
\hline $20-29$ & 34 & 17.0 \\
\hline $30-39$ & 56 & 28.0 \\
\hline $40-49$ & 51 & 25.5 \\
\hline $50-59$ & 44 & 22.0 \\
\hline above 60 & 15 & 7.5 \\
\hline \multicolumn{3}{|l|}{ Gender } \\
\hline Male & 106 & 53.0 \\
\hline Female & 94 & 47.0 \\
\hline \multicolumn{3}{|l|}{ Religion } \\
\hline Hindu & 172 & 86.0 \\
\hline Christian & 8 & 4.0 \\
\hline Muslim & 20 & 10.0 \\
\hline \multicolumn{3}{|l|}{ Education } \\
\hline Illiterate & 12 & 6.0 \\
\hline Primary & 57 & 28.5 \\
\hline Highschool & 49 & 24.5 \\
\hline PUC & 72 & 36.0 \\
\hline Diploma & 10 & 5.0 \\
\hline Graduate & 0 & 0 \\
\hline \multicolumn{3}{|c|}{ Income (annual in Rs) } \\
\hline$<11800$ & 197 & 98.5 \\
\hline$>11800$ & 3 & 1.5 \\
\hline \multicolumn{3}{|c|}{ Marital status } \\
\hline Married & 200 & 100.0 \\
\hline Unmarried & 0 & 0 \\
\hline \multicolumn{3}{|c|}{ Type of family } \\
\hline Nuclear & 172 & 86.0 \\
\hline Joint & 28 & 14.0 \\
\hline \multicolumn{3}{|c|}{ Colour of BPL card } \\
\hline Green & 177 & 88.5 \\
\hline Pink & 23 & 11.5 \\
\hline
\end{tabular}

Data presented in Table 1 shows that majority (56\%) of samples belongs to the age group of 30-39 years and are males (53\%) and belongs to Hindu religion (86\%). Most (36\%) of the samples had an education upto PUC and were coolie workers(49\%). The samples were married; $86 \%$ were from nuclear family and majority (98.5\%)had an annual income of less than Rs.11800. Only $11.5 \%$ had anthyodhaya card (pink colour) which indicates that these anthyodhya card holders are from very poor family.

\section{Description of knowledge scores of BPL families}

The knowledge scores of BPL families on BPL schemes were classified aspoor, average and good knowledge and ispresented in percentage.

$\mathbf{n}=\mathbf{2 0 0}$

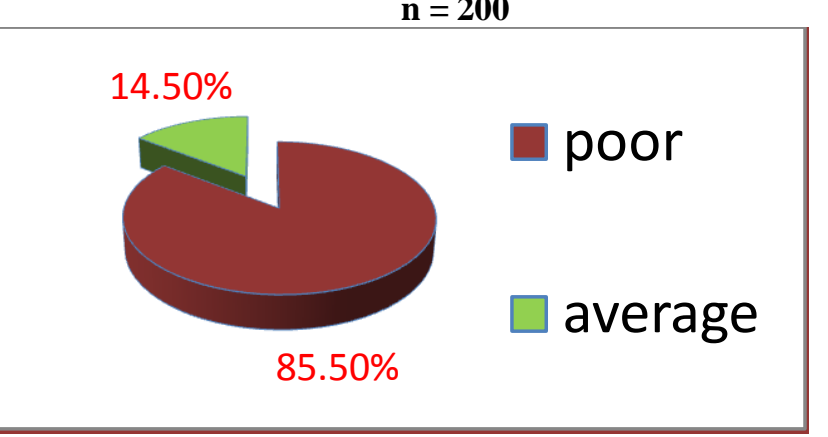

Fig 1: Pie diagram showing the Knowledge scores on BPL Schemes

The data presented in Figure 1 shows that majority (85.5\%) samples had poor knowledge, 14.5\% had average knowledge and no one had good knowledge on BPL schemes. 
Table 2: Utilization of BPL schemes. $\mathbf{n}=\mathbf{2 0 0}$

\begin{tabular}{|c|c|c|}
\hline Schemes & $\begin{array}{l}\text { Utilized } \\
(\%)\end{array}$ & $\begin{array}{l}\text { Not utilized } \\
(\%)\end{array}$ \\
\hline Vajpayee Arogyasri & 33 & 67 \\
\hline Basavavasathi scheme & 64 & 36 \\
\hline BPL ration scheme & 58 & 42 \\
\hline Nirmal Bharat Abhyian & 15.5 & 84.5 \\
\hline $\begin{array}{l}\text { Mahatma Gandhi National Rural Employment Gaurantee } \\
\text { Scheme }\end{array}$ & 14 & 86 \\
\hline SuvarnaGramodayaYojana & 4 & 96 \\
\hline Swarnajayanthi Gram SarojgarYojana & 19.5 & 80.5 \\
\hline RashtriyaSwasthiyaBimaYojana & 28 & 72 \\
\hline
\end{tabular}

Data presented in Table2 shows that among 200 samplesBasavaVasathi scheme (64\%) and BPL ration scheme $(58 \%)$ were the mostly utilized schemes. Utilization of other schemes were as follows: SuvarnaGramodayaYojana(4\%) Swarnajayanthi Gram SarojgarYojana(19.5\%), Mahatma Gandhi National Rural Employment Guarantee Scheme (14\%) and Nirmal Bharat Abhyian (15.5\%).

\section{Utilization of JananiSurakshaYojana}

Among 200 families 54 families were eligible for JananiSurakshaYojana. Data related to utilization were collected using utilization questionnaire on BPL schemes. Frequency and percentage was used to analyse the data.

Table 3: Utilization of JananiSurakshaYojana $\mathrm{n}=54$

\begin{tabular}{lll}
\hline Utilization scores & f & \% \\
\hline Not utilized & 12 & 22.2 \\
Utilized & 42 & 77.8 \\
\hline
\end{tabular}

Data presented in inTable 3 shows that majority(77.8\%) of the familes were utilized JananiSurakshaYojana.

\section{Utilization of BhagyalakshmiYojana}

Among 200 families 48 families were eligible for Bhagyalakshmi scheme. Data related to utilization were collected using utilization questionnaire on BPL schemes. Frequency and percentage was used to analyse the data.

Table 4: Utilization of BhagyalakshmiYojana $n=48$

\begin{tabular}{lcc}
\hline Utilization scores & f & \% \\
\hline Not utilized & 22 & 45.6 \\
Utilized & 26 & 54.2
\end{tabular}

Data presented in Table 4 showed that $54.2 \%$ of families are utilizing Bhagyalakshmi scheme

\section{Utilization of old age pension}

Among 200 families 112 families were with people above 65 years of age eligible for old age pension.Data related to utilization were collected using utilization questionnaire on BPL schemes. Frequency and percentage was used to analyse the data.

Table 5: Utilization of old age pension $\mathrm{n}=112$

\begin{tabular}{lcc}
\hline Utilization scores & f & \% \\
\hline Not utilized & 50 & 44.6 \\
Utilized & 62 & 55.4 \\
\hline
\end{tabular}

Data presents in Table 5 shows that only55.4\% of families were availing the old age pension scheme.

\section{Association between knowledge and selected variable}

$\mathrm{H}_{01}$ - there will be no significant association between the knowledge and selected variables like education, type of family and type of card they hold at 0.05 level of significance. 
Table 6: Association between knowledge and selected variables

\begin{tabular}{|c|c|c|c|c|c|}
\hline \multirow[t]{2}{*}{ Sample characteristics } & \multicolumn{2}{|c|}{$\begin{array}{c}\text { Knowledge } \\
\text { score category }\end{array}$} & \multirow[t]{2}{*}{$\mathrm{X}^{2}$} & \multirow[t]{2}{*}{ df } & \multirow[t]{2}{*}{$P$ value } \\
\hline & Poor & Average & & & \\
\hline \multicolumn{6}{|l|}{ Education } \\
\hline Illiterate & 12 & 0 & 11.866 & 4 & $0.018^{*}$ \\
\hline Primary (1-7) & 48 & 9 & & & \\
\hline High school & 45 & 4 & & & \\
\hline PUC & 56 & 16 & & & \\
\hline Diploma & 10 & 0 & & & \\
\hline \multicolumn{6}{|l|}{ Type of family } \\
\hline Nuclear & 144 & 28 & 4.118 & 1 & $0.042^{*}$ \\
\hline Joint & 27 & 1 & & & \\
\hline \multicolumn{6}{|l|}{ Type of card } \\
\hline Green & 152 & 25 & 0.168 & 1 & 0.682 \\
\hline Pink & 19 & 4 & & & \\
\hline
\end{tabular}

* Level of significance at $\mathrm{p}<0.05$

Data presented in Table 6shows that the chi-square value computed between knowledge and selected variables like education, type of family and type of card they holds. It shows thatthere is a significant association between education $\left(\chi^{2}=11.866, p<0.05\right)$ and type of family $\left(\chi^{2}=4.118, p<0.05\right)$ and there is no association between the knowledge and type of card they holds $\left(\chi^{2}=0.168, p>0.05\right)$. Hence the null hypothesis was accepted with regard to the type of card they holds.

\section{Knowledge and Utilization of BPL schemes}

\section{Discussion}

In the present study majority $(85.5 \%)$ samples had poor knowledge, $14.5 \%$ had average knowledge and no one had good knowledge on BPL schemesIt was supported by a cross sectional study conducted by Rohit A, Patil PS, Dixit UR, Chowti J V in 2012among rural BPL Families in Darward district in Karnataka.The study result showed that awareness regarding obstetric, medical services like JSYwere high(70\%) and other services like Vajpayee Arogyasri was low (4\%). ${ }^{4}$

In the present study the utilization of JSY was $77.8 \%$, BhagyalakshmiYojana 55.4\%, Vajpayee Arogyasri is $33 \%$ and Ration scheme was $58 \%$. It was supported by a cross sectional study conducted by Rohit A, Patil PS, Dixit UR, Chowti J V in 2012 regarding the utilization of Government Health Services and Schemes among rural BPL families in Darward district in Karnataka. The study result showed that Utilization of non-medical benefits like BhagyalakshmiYojana 90\%, ration scheme 93\% are high whereas Utilization of government health services like JSY, Vajpayee Arogyasri, are low(27.85\%), Schemes with monetary were benefits utilized more, Awareness regarding obstetric, medical services -high like JSY is $70 \%$ and other services like Vajpayee Arogyasri (4\%) is $10 w^{4}$.

In the present study the coverage of Nirmal Bharat Abhiyan in adopted villages was only $15.5 \%$. This contradicts the findings of another study conducted in Andhra Pradesh (AP) where a coverage status of $60 \%$ is reported point out that the analysis of field data reveals that AP has achieved a coverage status of $60 \%$ but the usage of toilet by the household is alarmingly low. The major funds include insufficient fund allocation as compared to water, lack of effective strategies for demand creation, no or low expenditure on IEC components etc. the study findings concluded that the government should concentrate on public private partnership which can accelerate solutions and enhance service provisions ${ }^{5}$.

\section{References}

[1]. Below poverty line [internet].2000. available from www.wikipedia.org

[2]. Ram F, Mohanthy S K, Ram U. Understanding the distribution of BPL cards: All India and selected states. Economic and Political Weekly 2009;(114/1).

[3]. Alkire S, Seth S. Determining BPL status: some methodological improvement. Oxford Poverty and Human Development Initiative Conference. 2008; New Delhi. [internet] Available from http://www.ophi.org.uk/wp-content/uploads/OPHI-RP-7a.pdf

[4]. RohitA,Patil P S, Dixit U R, Chowthi J V. Utilization Of Government Health Services And Schemes By Rural BPL Families. Unpublished Thesis SDMCMSH; Darward: 2012

[5]. D Rajashekar, Berg E, Ghatak M, Manjula R, Roy S. as Implementing Health Insurance: The Rollout of RashtriyaSwasthyaBimaYojana in Karnataka. Economic and Political weekly.2011; 41(20): 56- 63

[6]. Snehalatha M, Anitha V. Total Sanitation Campaign - Progress and Issues. WASHCost - CESS Working Paper No.11; 2011 